\title{
O pensamento decolonial e a educação crítica: repensando o ensino de línguas na atualidade.
}

\author{
Patrícia Christina dos Reis ${ }^{1}$ \\ Miriam Lúcia dos Santos Jorge 2
}

Resumo: Este artigo tem como objetivo discutir questões relacionadas ao ensino de línguas no Brasil, levando em consideração estudos sobre o pensamento decolonial e os estudos críticos, inspirados por Freire $(1997,2002)$, aqui considerado fundamental por sua abordagem humana e emancipatória. Inicialmente apresentamos três teóricos dos estudos decoloniais: Mignolo (2018), Quijano (2005) e Sousa Santos (2007). Discutimos como suas ideias nos fazem repensar o trabalho do professor de línguas, ressignificando suas práticas e propondo uma educação menos eurocêntrica, mais próxima das realidades locais. Enfatizamos a importância da desconstrução de mitos socialmente construídos sobre língua, com base em Makoni e Pennycook (2007) e, por fim, explicamos como Paulo Freire contribui para essa linha de pensamento, reforçando o discurso dos teóricos decoloniais. Concluímos o artigo, fazendo uma breve síntese do que foi discutido e propondo uma formação de professores que não se limite ao ensino das línguas em si, mas que se abra para uma discussão maior sobre o que é ser professor de línguas na atualidade.

Palavras-chave: ensino de línguas, pensamento decolonial, estudos críticos.

\section{Introdução}

Entendemos como práticas decoloniais aquelas que derivam do ato de "decolonizar" e que se baseiam numa perspectiva crítica emancipatória. Essas práticas contribuem para um novo entendimento de língua que se difere daquele criado na Modernidade, quando se acreditou que ela só se legitimaria, se fosse pura. Como referências para essa linha de pensamento, apontamos três nomes: Mignolo (2018), Quijano (2005) e Sousa Santos (2007).

1 Professora Assistente da UEA. Doutoranda em Estudos Linguísticos na UFMG. Bolsista do PROPG-CAPES/FAPEAM. reispatricia2003@yahoo.com.

2 Professora Associada da UFMG. Doutora em Linguística Aplicada.mlsj54@hotmail.com

\section{Gláuks: Revista de Letras e Artes-jan/jun. 2020 - Vol. 20, $N^{o} 1$}


Pensando nos avanços e desafios da formação dos professores de línguas no Brasil, consideramos importante observar a mensagem que os pensadores aqui citados nos trazem. Muito do comportamento dos professores e da forma como veem a profissão certamente é resultado de um sistema colonial que permanece entre nós desde a Modernidade, que define o que é conhecimento e que hierarquiza saberes. A decolonização do conhecimento surge como uma forma de voltar a educação para o aluno brasileiro, especialmente o aluno de regiões que se distanciam do norte global, aqui entendido como um grupo privilegiado e excludente em oposição ao sul, formado pelos grupos minoritarizados.

Em busca de um sistema mais igualitário é que se faz importante a formação do professor para uma educação crítica. Freire $(1997,2002)$, para quem a educação é uma forma de interferir no mundo, aparece nesse contexto como uma das principais fontes para se pensar a educação fora do centro, nos fazendo voltar os olhos para regiões periféricas, muitas vezes apagadas, esquecidas.

\section{O pensamento decolonial}

O que Quijano (2005) propõe para decolonizar os saberes é uma reconstituição epistêmica, uma vez que somos dominados por uma epistemologia colonial que se desdobra em várias áreas das nossas vidas. Seguindo a mesma linha de raciocínio, Mignolo (2018) enfatiza que precisamos questionar os fundamentos da epistemologia ocidental se quisermos propor a decolonização do conhecimento. O que ele sugere é que sigamos Quijano em sua proposta de "nos desprendermos da matriz colonial do poder", que provoquemos rupturas epistêmicas e que remodelemos o saber e o ser, negando o racismo, o sexismo, as estruturas políticas e econômicas imperialistas, o conhecimento e o entendimento controlados por um imaginário local que se pretende universal, a vida em todos os aspectos: da vida humana à vida do planeta, que estejam sendo controladas por modelos masculinos e patriarcais (Mignolo, 2018, p. 126). 
Segundo Mignolo (2018), a decolonialidade é a resposta de pessoas que não querem ser oprimidas, exploradas e espoliadas por uma matriz de poder fundada na Modernidade, que privilegia determinadas línguas, culturas e povos. O autor enfatiza que os rótulos que as pessoas hoje recebem, em relação à cor ou à orientação sexual, por exemplo, e as classificações daquilo que é ou não é conhecimento válido são heranças da modernidade que chegaram até nós através de diferentes formas de enunciação como discursos científicos e midiáticos, educação e pedagogia, do jardim de infância até a universidade. O confronto travado entre conhecimento local e o conhecimento que os especialistas consideram válido (aquele produzido na academia) é também discutido por Rajagopalan (2005), assim como Canagarajah (2005) que propõe uma reconstrução das práticas e conhecimentos locais.

Igualmente, o trabalho de Sousa Santos (2007) confirma o impacto da Modernidade na forma de pensar da sociedade de hoje. Para ele, uma linha abissal que divide o pensamento moderno ocidental causa exclusões nas relações políticas e culturais do mundo contemporâneo:

\footnotetext{
O pensamento moderno ocidental é um pensamento abissal consiste num sistema de distinções visíveis e invisíveis, sendo que estas últimas fundamentam as primeiras. As distinções invisíveis são estabelecidas por meio de linhas radicais que dividem a realidade social em dois universos distintos: o "deste lado da linha" e o "do outro lado da linha". A divisão é tal que "o outro lado da linha" desaparece como realidade, torna-se inexistente e é mesmo produzido como inexistente. Inexistência significa não existir sob qualquer modo de ser relevante ou compreensível. Tudo aquilo que é produzido como inexistente é excluído de forma radical porque permanece exterior ao universo que a própria concepção de inclusão considera como o "outro" (SOUZA SANTOS, 2007, p. 71).
}

Ele analisa as implicações dessa divisão para a ciência e propõe uma reflexão sobre a diferença entre a ciência como pensamento monopolista e a ciência como parte de uma ecologia de saberes. Sousa Santos nos leva a entender que a construção epistemológica de uma ecologia de saberes é uma tarefa bastante difícil e precisa ser feita de forma coletiva. É preciso que nos integremos por meio de um "pensamento pós-abissal", que tenha por premissa "a idéia da inesgotável diversidade epistemológica do mundo, o reconhecimento da existência de uma pluralidade de formas de conhecimento além do conhecimento científico" 
(SOUSA SANTOS, 2007, p. 85). Para ele é preciso haver um descentramento dos pólos de conhecimento, de forma que universidades ou centros de pesquisa não sejam considerados os lugares exclusivos dos saberes.

\section{A língua como construção social}

Segundo Makoni e Pennycook (2007), a língua é uma invenção social, cultural e política. As formas como as línguas são hierarquizadas no mundo, dentro de um país ou até mesmo dentro de uma comunidade podem ser problemáticas e injustas. Quando línguas são introduzidas em certas comunidades, elas criam ou acentuam diferenças sociais. São muitas vezes ensinadas em instituições fechadas, direcionadas a um determinado público, deixando parte significativa da comunidade de fora.

Ainda hoje no Brasil existem comunidades que são excluídas por causa de línguas dominantes que impõe as regras. As línguas indígenas brasileiras têm sido gradualmente ameaçadas pela presença de línguas colonizadoras, como o português e o inglês. Na verdade, o efeito da língua inglesa no Brasil é percebido por todos os cantos, assim como é a exclusão que ela provoca. Grande parte da população brasileira não tem acesso ao idioma através de instituições formais, porém estabelecem contato com a língua através de experiências particulares, em espaços informais, que também merecem ser considerados quando se pensa em aquisição de língua inglesa no Brasil.

A partir do momento em que consideramos a língua como uma ferramenta ideológica, que separa grupos, precisamos considerar também a maneira como seu estudo tem sido proposto nas escolas do nosso país. Ainda existem forças hegemônicas que controlam o sistema escolar, o planejamento de currículos e a atuação dos professores. Certamente observamos uma valorização de certos grupos sociais nos livros didáticos ou a criação de situações de uso da língua inimagináveis para determinadas classes da sociedade brasileira. É preciso voltar o olhar para as realidades regionais, para os conhecimentos que podem ser

\footnotetext{
Gláuks: Revista de Letras e Artes-jan/jun. 2020 - Vol. 20, $N^{o} 1$
} 
produzidos com base nas experiências locais, sem privilegiar determinados segmentos, determinadas línguas, sem nenhuma forma de imperialismo linguístico.

Kumaravadivelu (2012) vê a necessidade de uma ruptura epistêmica que acabe com a dependência que professores de inglês têm em relação aos sistemas de ensino baseados no modelo ocidental. Para ele, existem nós terminológicos que fazem com que o professor trate de forma superficial desafios que precisam ser confrontados de forma mais radical. Romper epistemicamente com sistemas de conhecimento que ainda carregam legados do colonialismo seria a solução.

As promessas que o inglês geralmente traz consigo são de ascensão social e econômica, para todos que aprendem a língua. Visão que não passa de um mito, se seguirmos a linha de pensamento de Pennycook (2007) para quem a existência de uma língua voltada para um público de posição social privilegiada serve para criar mais barreiras que oportunidades.

Antes de prosseguir com sua tese de que o inglês é um mito, Pennycook nos leva a questionar o papel dos livros de inglês, dos usuários do idioma e dos departamentos de língua inglesa. O que, então, estão fazendo? Será que não estão sendo excludentes, deixando de fora alguns países, algumas culturas ou algumas formas de conhecimento?

Partindo para uma reflexão sobre o argumento de Pennycook e o seu impacto na forma como ensinamos inglês, nos perguntamos: será que essa obsessão, que temos nós professores, para que os alunos dominem o inglês padrão não seria desnecessária? Não seria esta uma luta um tanto quanto frustrante, já que são muitos os fatores que impossibilitam a sua execução? O ensino de inglês pode oferecer mais a esses alunos do que uma busca pelo domínio do inglês padrão? O que está sendo valorizado no ensino de inglês nas escolas públicas do nosso país? Se seu objetivo é a comunicação, não seria possível chegar a ela sem ter que sistematizar o seu ensino ou fazer da língua um ideal longe de ser alcançado? O que podemos fazer nesse sentido? Como nossos livros didáticos podem ajudar? Conseguiremos construir uma escola mais humanizada e menos tecnicista? Nesse sentido, é de fato importante seguir as orientações de Pennycook e começar a desmistificar o papel do inglês e sua função na educação.

Gláuks: Revista de Letras e Artes-jan/jun. 2020 - Vol. 20, $N^{o} 1$ 


\section{A formação de professores e de agentes críticos}

Ensinar línguas nos dias de hoje é uma tarefa que vai além da questão linguística. É um trabalho que envolve tanto o professor quanto seus alunos em questões sociais, culturais e econômicas. Concordamos com a explicação de Edmundo e Mulik (2017) ao apontar a relação entre agência e criticidade. Segundo eles, o "conceito de agência é caro à formação de professores e está bastante vinculado ao desenvolvimento crítico, pois esse último recai na possibilidade de preparar indivíduos para mudanças de atitude” (p. 24710).

No ato de ensinar, o professor consciente das questões que precisam ser discutidas e problematizadas em sala de aula, leva seus alunos a uma reflexão crítica e eventualmente forma agentes que poderão atuar em suas comunidades. Essa tendência é marca da globalização e, segundo Monte Mór (2014, p. 242):

\footnotetext{
Novas habilidades integram o ideário da globalização e cresce a preocupação com uma formação que leve ao engajamento social, à agência, à participação crítica para a vivência e convivência condizente às sociedades com as características nelas percebidas nos últimos tempos, conforme ressaltam os estudiosos da área de educação, como é o caso de Lankshear e Knobel (2003, 2011), Cope e Kalantzis (2000) Kalantzis e Cope (2008), e outros pesquisadores dos novos letramentos e multiletramentos.
}

Programas de professores precisam estar voltados para esse fim e muitos têm sido reestruturados nos últimos anos. Zeichner (2016, p. 151) faz uma crítica aos programas de formação de professores nos Estados Unidos, mostrando que eles falham por não se preocupar com elementos básicos da justiça social, como um cenário educacional diverso, que reivindique direitos iguais na sociedade. Segundo ele, muitos programas focam somente nos aspectos técnicos do ensino, no aumento das notas dos estudantes e não incentivam o professor a exercitar seu poder de julgamento na sala de aula, nem adaptar suas aulas às necessidades de seus alunos.

Essa é uma característica da educação neoliberal que vem sendo adotada por muitas instituições em todo o mundo. Estratégias como a publicação de notas altas dos alunos nos sites das escolas são comuns para atrair pais e aumentar a procura pela escola (SAVAGE,

Gláuks: Revista de Letras e Artes-jan/jun. 2020 - Vol. 20, $N^{o} 1$ 
2017). Por outro lado, Hara e Sherbine (2018) acreditam que a visão do professor pode, em certas circunstâncias, servir de ímpeto para a resistência a pressões neoliberais. Essa visão precisa ser trabalhada desde a formação docente em programas que levem o professor em formação a compreender o papel que pode desempenhar como agente de resistência, não reprodutor de discursos hegemônicos.

A crítica de Zeichner aqui apresentada, quando aplicada aos programas de formação de professores nas universidades, vem valorizar uma carreira docente que não seja tecnicista, mas sim humana e aberta a diferenças e diversidades. Em outro artigo, o autor discute o papel para o qual diversos programas têm preparado professores, questionando quem deve preparálos, quando e onde essa preparação deve acontecer e qual deve ser o conteúdo desse programa de preparação (ZEICHNER, 2014). Na primeira parte do artigo ele apresenta um panorama da educação de professores nos Estados Unidos. Ele fala das diversas formas de ingresso à carreira docente que já existiram no país, incluindo diferentes escolas de formação, até chegar a vez das universidades, nos anos 90. Depois apresenta as lacunas na escolarização e críticas à educação de professores na universidade, apontando um acesso desigual que acontece em todos os níveis de escolaridade.

Zeichner (2014) também chama atenção para aqueles alunos que se veem obrigados a aprender fora do contexto e interagir com o conhecimento de formas artificiais. Discute ainda o fato de professores de determinadas comunidades receberem formação diferente dos demais (p. 563). Nesse aspecto, a preocupação do autor se compara à nossa. É importante que as políticas públicas no Brasil sejam fortalecidas a fim de garantir a todos os professores, do Oiapoque ao Chuí, formação inicial e continuada com a mesma qualidade.

Uma das preocupações da Linguística Aplicada tem sido dar visibilidade a grupos de professores minoritarizados, como afirmam Kleiman, Vianna e De Grande (2019, p. 738):

Uma agenda de pesquisa em LA que assuma a continuidade na transformação, que hoje caracteriza as vertentes linguístico-enunciativo-discursivas numa perspectiva etnográfica e interpretativista, abre espaço para projetos que permitam ouvir a voz dos participantes de pesquisa na esfera acadêmica e valorizar seus conhecimentos, mesmo quando eles pertencem a grupos historicamente excluídos da produção de conhecimento legitimado na sociedade, i.e. grupos social e economicamente 
vulneráveis - mulheres, negros, indígenas, surdos, grupos homoafetivos, transexuais e, também, professores e alunos de escolas públicas - com o objetivo de conferir visibilidade a seus saberes, seus letramentos, seus processos de formação.

São esses grupos, que por sua vez formarão novos sujeitos, influenciados por suas experiências e histórias de vida. Nesse trabalho de formação de agentes críticos o professor conta com um poderoso aliado: o livro didático. Dele poderão surgir ideias que representarão o ponto de partida para discussões e engajamento dos estudantes.

A discussão sobre o livro didático nos aponta para um documento importante a ser considerado pelo professor: a BNCC (Base Nacional Comum Curricular), que é uma referência nacional obrigatória para a elaboração ou adequação dos currículos escolares e propostas pedagógicas (BRASIL, 2018, p. 5). O documento vem destacar a importância do ensino de inglês para o agenciamento crítico dos estudantes e para o exercício da cidadania ativa.

Existe hoje um agravante que fragiliza ainda mais as licenciaturas em inglês: a alta oferta de cursos de idiomas no mercado. Há uma constante comparação entre técnicas de ensino e tempo de aquisição do inglês na universidade e relação aos cursos de idiomas. No entanto, é necessário enfatizar que as licenciaturas formam mais que conhecedores do idioma, formam professores, possuidores de uma reflexividade crítica sobre suas práticas docentes e sobre seu papel na educação.

Nóvoa (1992) propõe uma reflexão centrada na atuação profissional dos professores, destaca o papel da Universidade no processo de formação docente e enfatiza a importância de uma educação contínua que leve o professor a uma reflexão crítica sobre sua atuação. Para ele, "a formação não se constrói por acumulação (de cursos, de conhecimentos ou de técnicas), mas sim através de um trabalho de reflexividade crítica sobre as práticas e de (re)construção permanente de uma identidade pessoal" (NÓVOA, 1992, p. 13).

Um exemplo de educadora engajada na reflexividade crítica é Hooks (1997). Foi com base nos ensinamentos de Paulo Freire e na sua experiência como aluna de escolas para 
negros no sul dos Estados Unidos, que ela começou a traçar suas próprias metas pedagógicas, pensando sempre na educação como uma forma de libertação.

O que também merece ser destacado no discurso da autora é o seu desejo de ir sempre ao encontro das necessidades dos seus alunos. Esse esforço é o segredo para uma prática de ensino justa e igualitária. É pensar no motivo que traz cada aluno para a sala de aula e no importante papel que o professor ali realiza: o de promover momentos de aprendizagem que não sejam simplesmente baseados em normas e padrões, que sejam momentos de transgressão, baseados nas demandas específicas dos alunos e nas novas formas de se compreender a educação.

\section{Contribuições freirianas}

Freire (1997), em Pedagogia da Esperança, fala da época em que viveu em exílio, no Chile, e como essa experiência moldou o seu modo de ver o mundo, seu pensamento e sua escrita. Nessa época, escrevia o livro Pedagogia do Oprimido, e a oportunidade de ter vivido a atmosfera histórica da época o ajudou a encontrar respostas para dúvidas que tinha antes de ser exilado. O que também influenciou a escrita do seu livro foi o seu convívio com camponeses, pescadores e trabalhadores urbanos, cujos modos de falar ele admirava e respeitava. Freire (1997) nos relata como seu pensamento pedagógico foi se constituindo até chegar ao momento da escrita de Pedagogia da Esperança, em que discute a esperança com que escreveu a Pedagogia do Oprimido.

Para o autor, escrever seu livro foi uma tarefa política. E essa politicidade, a impossibilidade de ser neutro, é que demanda do educador sua eticidade. Freire (1997) apresenta o ato de ensinar como algo que vai além de uma exposição de conteúdos, é um ensinar que envolve um posicionamento, um respeito mútuo. É um ato criador, crítico e não mecânico.

Em Pedagogia da Autonomia, Freire (2002) apresenta uma série de proposições que podemos associar ao trabalho do professor de línguas. Aqui destacamos cinco delas. A 
primeira nos lembra que ensinar exige respeito aos saberes dos educandos. Freire fala da importância de trabalharmos na sala de aula os saberes socialmente construídos na prática comunitária e sua relação com os conteúdos ensinados na escola. Sua proposta é "estabelecer uma necessária 'intimidade' entre os saberes curriculares fundamentais dos alunos e a experiência social que eles têm como indivíduos".

A segunda proposição vem ressaltar que ensinar exige estética e ética. Segundo Freire (2002) podemos ser tentados a escolher os desvios fáceis e não enfrentar as dificuldades que os caminhos verdadeiros podem nos colocar. Atuar com ética é seguir o caminho verdadeiro, mesmo que ele represente dores e sofrimento. É pensar no bem do aluno e da escola e não somente em si mesmo.

Para o professor, muitas vezes, pode ser mais fácil e viável, por exemplo, não fazer ajustes no material didático, mesmo que este não venha ao encontro das necessidades de determinado grupo. Ao contrário, o trabalho do professor que dedica parte do seu tempo nessa adaptação pode ser entendido como uma atitude ética. Ao contrário do que muitos pensam, ética não está somente relacionada a princípios e regras, mas à atenção que damos ao outro, ato que se materializa nas escolhas que fazemos: escolha de material, da forma de avaliação e de atividades que fortaleçam a relação com o próximo.

A terceira proposição nos lembra que ensinar exige reflexão crítica sobre a prática. $O$ professor em formação (inicial e contínua) precisa estar sempre refletindo sobre sua atuação. Freire argumenta que é pensando criticamente a prática de ontem que se pode melhorar a próxima prática. Uma forma encontrada pela universidade para incentivar o professor da educação básica a refletir sobre sua prática são os cursos de educação continuada, muitas vezes organizados para promover a reflexão crítica sobre a docência.

A quarta proposição ressalta que ensinar exige comprometimento, que se reflete na forma como lidamos com o conhecimento e com nossos alunos. Se nos comprometemos a ser professor, precisamos estar numa constante busca de conhecimento. Se nos comprometemos com nossos alunos, precisamos ter com eles um relacionamento verdadeiro, justo e solidário. Nossa presença é política e deve ser firmemente marcada.

\section{Gláuks: Revista de Letras e Artes-jan/jun. 2020 - Vol. 20, $N^{o} 1$}


A quinta proposição de Freire que aqui destacamos nos lembra que ensinar exige saber escutar. Freire aponta uma condição para o ato de saber escutar: "não é falando aos outros, de cima para baixo, sobretudo, como se fôssemos os portadores da verdade a ser transmitida aos demais, que aprendemos a escutar" (FREIRE, 2002, p.43). Essa fala vem estabelecer um lugar para o professor que não é superior ao seu aluno. A escuta verdadeira ocorre lado a lado.

Ao valorizar a escuta, Freire nos remete às duas últimas proposições do seu livro: "Ensinar exige disponibilidade para o diálogo" e "Ensinar exige querer bem aos educandos". Querer bem e estar aberto ao diálogo, com atenção, são atitudes de um professor que sai da sua posição de "quem sabe" para a posição de "quem quer aprender".

Menezes de Souza e Monte Mór (2018) refletem sobre uma pergunta, a um deles direcionada em um congresso no exterior, que vem somar às questões que neste artigo levantamos: por que nós da terra de Paulo Freire ainda defendemos uma educação crítica? Já não implementamos todas as teorias e reflexões freirianas em nossos programas educacionais? A resposta pode ser resumida com poucas palavras: no mundo ainda há necessidade de justiça e mudança. O que os autores sugerem é que Freire seja atualizado, que entre em diálogo com novas perspectivas, como a decolonial que aqui apresentamos.

\section{Considerações Finais}

Neste artigo procuramos apresentar questões que vêm sendo discutidas no campo da Linguística Aplicada, mais especificamente entre os linguistas críticos e decoloniais. Iniciamos com uma explicação sobre o que é uma prática decolonial e que teóricos a representam. Citamos Mignolo (2018), Quijano (2005) e Sousa Santos (2007) como exemplos de teóricos que enfatizam a importância de nos distanciarmos cada vez mais das regras eurocêntricas.

Em seguida, citamos estudiosos que se preocupam em descontruir crenças, como a de uma língua pura, e que defendem modos de pensar menos preconceituosos, respeitando a diversidade e pluralidade linguística dos povos. Sugerimos Makoni e Pennycook (2007) como

Gláuks: Revista de Letras e Artes-jan/jun. 2020 - Vol. 20, $N^{o} 1$ 
referências para o estudo da língua como um construto social e para entendermos os mitos que a envolvem.

Ressaltamos a importância de uma conscientização dos professores em relação a essas novas perspectivas, propondo uma formação que seja reflexiva, que não seja tecnicista e que considere os alunos das diversas localidades e suas necessidades. Na reflexão sobre o processo de formação crítica desses professores, citamos a proposta de Zeichner (2006) que vem defender uma prática educativa aberta a diferenças, que forme agentes de resistência e não reproduza discursos hegemônicos.

Logo após, identificamos na agenda da Linguística Aplicada espaços para grupos minoritarizados de professores, que precisam ser ouvidos, assim como apontamos a necessidade de discussões em torno do livro didático e da BNCC. Defendemos as Licenciaturas, duramente criticadas na atualidade, e citamos Nóvoa (1992) para mostrar que podem ser elas espaços de reflexão crítica e configuração profissional.

Concluímos o artigo com proposições de Paulo Freire uma vez que elas encorajam mudanças necessárias no cenário educacional em que estamos. Se o ensino de línguas encontra no discurso decolonial fundamentos para uma prática mais justa e adequada à nossa realidade, temos que admitir que a pedagogia crítica, fundamentada nos pensamentos de Freire, será um alicerce firme para essa nova construção. Ela nos ensina a ler o mundo para transformá-lo. Pensar criticamente sobre as práticas que temos exercido enquanto professores e sobre a relação que temos mantido com os nossos alunos é uma forma de nos prepararmos para as decisões que precisam ser tomadas.

Decolonizar o ensino de línguas no Brasil implica várias mudanças, desde as que se referem a políticas públicas até as comportamentais. O que cabe a nós, enquanto pesquisadores e professores dos Estudos Linguísticos é propor reflexões e discussões sobre o tipo de educação linguística que queremos e precisamos. Esperamos que este artigo seja uma contribuição relevante para esse grupo de estudos e que tenhamos deixado claro a mensagem que pretendíamos transmitir, a da possibilidade de uma decolonização do ensino de línguas, guiada por um pensamento humano e emancipatório. Que continuemos trabalhando por um ensino que seja aberto a diferenças, que ofereça formas de intervenção no mundo e por uma 
formação de professores que não se restrinja a ensinar conteúdos e técnicas para aplicá-los, mas que seja uma constante busca por formas libertadoras de lidar com o conhecimento.

\section{Referências bibliográficas}

BRASIL. Base Nacional Comum Curricular: Educação Infantil e Ensino Fundamental. Brasília: MEC/Secretaria de Educação Básica, 2018.

CANAGARAJAH, S. Reclaiming the Local in Language Policy and Practice. New York: Routledge, 2005.

EDMUNDO, E. G. S.; MULIKI, K. B. Agência docente e criticidade na formação inicial de professores de línguas. In: Anais do XIII EDUCERE. Curitiba 2017. p. 24703-24717.

FREIRE, P. Pedagogia da Autonomia: saberes necessários à prática educativa. 25ed. São Paulo: Editora Paz e Terra, 2002.

FREIRE, P. Pedagogia da Esperança: um reencontro com a Pedagogia do Oprimido. Rio de Janeiro: Editora Paz e Terra, 1997.

HARA, M.; SHERBINE, K. Be[com]ing a teacher in neoliberal times: The possibilities of visioning for resistance in teacher education. Policy Futures in Education. Vol 16. p. 669-690. Sage, 2018. Disponível em: < https://journals.sagepub.com> Acesso em 27 de abril de 2020.

HOOKS, B. Teaching to Transgress: education as the practice of freedom. New York: Routledge, 1994.

KLEIMAN, A. B.; VIANNA, C. A. D.; DE GRANDE, P. B. A Linguística Aplicada na contemporaneidade. Calidoscópio. v. 17, n. 4, p.724-742, dezembro 2019.

KUMARAVADIVELU, B. Individual identity, cultural globalization and teaching English as an international language: the case for an epistemic break. In: ALSAGOFF, L.; RENANDYA, W.; HU, G., McKAY, S. (Eds). Teaching English as an International Language: Principles and Preactices. New York: Routledge, 2012, p. 9-27.

MAKONI, S., PENNYCOOK, A. (Eds.). Disinventing and Reconstituting Languages. USA: Multilingual Matters, 2007.

Gláuks: Revista de Letras e Artes-jan/jun. 2020 - Vol. 20, $N^{o} 1$ 
MENEZES DE SOUZA, L. M. T.; MONTE MÓR, W. Afterword - Still Critique? Revista Brasileira de Linguística Aplicada. v. 18, n. 2, p. 445-450, 2018.

MIGNOLO, W. The Decolonial Option. In: MIGNOLO, W.; WALSH, C. On Decoloniality: Concepts, Analytics, Praxis. Durham: Duke Uiversity Press, 2018. p. 105-152.

MONTE MÓR, W. Convergência e diversidade no ensino de línguas: expandindo visões sobre a "diferença". Polifonia, Cuiabá, MT, v. 21, n. 29, p. 234-253, jan-jul., 2014.

NÓVOA, A. Formação de professores e profissão docente. In: NÓVOA, A. Os professores e a sua formação. Lisboa: Dom Quixote, 1992. p. 13-33.

PENNYCOOK, A. The Myth of English as an International Language. In: MAKONI, S., PENNYCOOK, A. (Eds.). Disinventing and Reconstituting Languages. USA: Multilingual Matters, 2007. P. 90-115

QUIJANO, A. Colonialidade do poder. Eurocentrismo e América Latina. In: LANDER, E. (org.) A colonialidade do saber: eurocentrismo e ciências sociais. Perspectivas latinoamericanas. Buenos Aires: CLACSO, Conselho Latinoamericano de Ciencias Sociales, 2005, p. $117-142$.

RAJAGOPALAN, K. The Language Issue in Brazil: When Local Knowledge Clashes With Expert Knowledge. In: CANAGARAJAH, S. Reclaiming the Local in Language Policy and Practice. New York: Routledge, 2005. p. 99-121.

SAVAGE, G. Neoliberalism, education and curriculum. In: GOBBY, B.; WALKER, R. (orgs.) Powers of Curriculum: Sociological Perspectives on Education. South Melbourne, Vic.: Oxford University Press Australia and New Zealand,_2017, p. 143-165.

SOUSA SANTOS, B. Para além do Pensamento Abissal: das linhas globais a uma ecologia dos saberes. Novos Estudos, 79. p. 71-94. São Paulo: CEBRAP, 2007.

ZEICHNER Advancing Social Justice and Democracy in Teacher Education: Teacher Preparation 1.0, 2.0, and 3.0. Kappa Delta Pi Record. p. 150-155. Oct-Dec 2016. 


\title{
Decolonial thinking and critical education: rethinking language teaching nowadays
}

\begin{abstract}
This article aims to discuss issues related to language teaching in Brazil, taking into account studies on decolonial thinking and critical studies, inspired by Freire (1997, 2002), considered fundamental here for his human and emancipatory approach. Initially we present three decolonial studies theorists: Mignolo (2018), Quijano (2005) and Sousa Santos (2007). We discuss how their ideas make us rethink the work of the language teacher, giving new meaning to her/his practices and proposing a less Eurocentric education, closer to local realities. We emphasize the importance of deconstructing socially constructed myths on language, based on Makoni and Pennycook (2007) and, finally, we explain how Paulo Freire contributes to this line of thought, reinforcing the decolonial theorists' discourses. We conclude the article, making a brief synthesis of what was discussed and proposing teacher training that is not limited to the teaching of languages itself, but that opens up to a greater discussion on what it is to be a language teacher nowadays.
\end{abstract}

Keywords: language teaching, decolonial thinking, critical studies.

Gláuks: Revista de Letras e Artes-jan/jun. 2020 -Vol. 20, $N^{o} 1$ 